\title{
Professores universitários que usam a tecnologia de informação e comunicação no ensino de matemática: quem são eles?
}

\author{
University teachers to use technology information and communication in \\ the teaching of mathematics: who are they?
}

Douglas Marin

douglasmarin2007@gmail.com

\begin{abstract}
Resumo
Este artigo apresenta resultados de uma pesquisa que procurou compreender como professores do ensino superior estão usando tecnologia da informação e comunicação (TIC) quando ministram suas aulas de Cálculo. Os dados são provenientes de entrevista com professores que, em algum momento de sua prática docente, utilizam TIC para ensinar Cálculo. Com esses relatos, foi possível fazer uma discussão acerca do perfil do professor do ensino superior que faz uso de TIC, contemplando os seguintes aspectos: tempo de docência; tempo de utilização de TIC; a formação dos professores; as instituições em que trabalham; as condições do trabalho docente; a motivação; o preparo e o envolvimento dos professores. Espera-se, com isso, contribuir para a formação de professores do ensino superior para o uso de TIC em sala de aula.
\end{abstract}

Palavras-chave: Ensino de matemática. Tecnologia de informação e comunicação. Educação Matemática.

\begin{abstract}
This paper presents results of a research which aim was to understand how university teachers use information and communication technology (ICT) when teaching Calculus. Data are from interviews with teachers who had already tried ICT for such. Based on these, a discussion of the following aspects was made: teaching experience, duration of use of ICT, teacher training, the institutions where they work, the conditions of teaching, motivation, preparation and involvement of teachers. This study may help to structure teacher education program for the use of ICT at the university.
\end{abstract}

Keywords: Teaching of mathematics, Information technology and communication, Mathematics Education. 


\section{Introdução}

O uso de tecnologia de informação e comunicação (TIC) no ensino de matemática tem sido recomendado pelos especialistas pelo fato de ampliarem as possibilidades de atividades em que os alunos possam trabalhar com diferentes representações tais como uma tabela, gráficos e expressões algébricas, de forma rápida e articulada. Isso contribui para a exploração dos diferentes conceitos matemáticos. Em particular, no ensino superior, o uso de TIC tem sido especialmente recomendado para a disciplina de Cálculo.

Nos trabalhos de Koga (1998), Palis (1995), Nasser (2004), são levantados aspectos preocupantes com a disciplina de Cálculo, que é uma das com maior índice de reprovação. Os mais citados, por exemplo, são:

- O Cálculo é uma disciplina de transição entre o ensino médio e o ensino superior;

- O Cálculo, por ser uma disciplina que, em muitas universidades, está no primeiro semestre, possui um grande número de alunos em sala;

- O aluno vem com uma formação precária do ensino médio, então o professor tenta sanar algumas dificuldades e acaba condensando os conteúdos que devem ser ministrados na disciplina porque a carga horária é insuficiente e, com isso compromete esta e outras disciplinas que dependem do Cálculo;

- A grande quantidade de matéria a ser exposta faz com que a aula siga um ritmo acelerado, havendo pouco espaço para o aluno investigar.

Há vários projetos e iniciativas nacionais e internacionais para estudar e propor soluções para o problema com essa disciplina. Algumas soluções são apontadas, como os programas de monitorias; a inclusão de disciplinas preparatórias, como o pré-cálculo; a participação do professor em grupo de pesquisas; e o apoio do governo através de órgão de fomento.

Para Palis (1995, p. 25), "uma das possibilidades de ação pedagógica visando à superação de alguns desses impasses é a utilização de novas tecnologias computacionais como ferramentas didáticas nos cursos de matemática”.

Pesquisas como em Penteado Silva (1997), Borba; Penteado (2001), Penteado (1999; 2000), tem mostrado que o uso de TIC é bastante restrito, muito embora ela possa facilitar o estudo de diversos conteúdos. A capacidade técnica das máquinas possibilita planejar atividades de ensino, antes impensáveis com o uso de lousa e giz. Para o ensino de matemática, por 
exemplo, há vários softwares que permitem explorar os conceitos de matemática de uma forma mais dinâmica e detalhada.

A restrição se deve, entre outros fatores, pela formação dos professores que, de maneira geral, não contempla um estudo sobre o ensino com o uso de TIC. No caso de professores do ensino superior a situação é mais precária, uma vez que sua formação pedagógica apenas recentemente tem sido problematizada nas pesquisas.

O presente texto é uma contribuição para esta área, visto que apresenta resultados de uma pesquisa cujo objetivo foi compreender como os professores do ensino superior estão usando TIC quando ministram suas aulas de Cálculo, uma disciplina da área de matemática. A discussão é baseada em dados provenientes de entrevistas com professores que ministram essa disciplina em diversos cursos de graduação. Procurou-se conhecer: o tipo de TIC que o professor utiliza; o que o levou a optar por fazer uso de TIC para ensinar Cálculo; a formação que teve para fazer isso; quais atividades são propostas para os alunos e quais vantagens e desvantagens percebe no uso de TIC no ensino de Cálculo.

As entrevistas foram feitas com treze professores do ensino superior, que fazem ou fizeram uso em algum momento da sua prática docente de TIC na disciplina Cálculo. Importante salientar que esta pesquisa não se limitou ao curso de Matemática, mas em todos os cursos onde consta no currículo esta disciplina, tais como Engenharia, Biologia, entre outros. Os participantes receberam os seguintes nomes fictícios: Bárbara, Marta, Neide, Renata, Roberta, Ronaldo, Rosa, Rose, Sandro, Solange, Valdemar, Verônica e Wagner.

Para auxiliar na discussão dos dados, foi feito um estudo da literatura sobre a docência e formação universitária e o uso de TIC. É sobre isso que trata a próxima seção.

\section{A docência e formação universitária e o uso de TIC}

Alguns estudos apontam que a Universidade no Brasil sofreu influências de modelos europeus que predominaram em diferentes momentos históricos (PIMENTA; ANASTASIOU, 2002; PACHANE, 2003). O marco inicial da Educação Superior no Brasil foi em 1572, com a criação dos cursos de Arte e Teologia no Colégio dos Jesuítas da Bahia. Mas, seu desenvolvimento ganhou força apenas a partir de 1808, quando o rei D. João VI e a corte portuguesa transferiram-se de Portugal para o Brasil. 
O modelo de ensino criado neste período era baseado na escola francesa e estava preocupado em dar ênfase na formação de profissionais liberais (Direito, Medicina, Farmácia e Engenharia) e de burocratas, necessários ao Estado.Para isso, usavam um processo de ensino em que

\begin{abstract}
os conhecimentos e experiências profissionais são transmitidos de um professor que sabe e conhece para um aluno que não sabe e não conhece, seguido por uma avaliação que diz se o aluno está apto ou não para exercer aquela profissão. Se o aluno vai bem ele recebe o diploma ou certificado de competência que permite o exercício profissional. Caso contrário, repete o curso (MASETTO, 1998, p.10)
\end{abstract}

Entretanto, quem era esse professor que atuava dentro daquele modelo?

Inicialmente, os professores das primeiras escolas superiores brasileiras eram pessoas formadas pelas Universidades europeias. Mas, com o crescimento e a expansão dos cursos superiores, o corpo docente precisou ser ampliado e passou a ser recrutado entre profissionais renomados, com sucesso em suas atividades profissionais (PACHANE, 2003). Masetto (1998) ressalta que os professores eram convidados com a tarefa de ensinar seus alunos a serem tão bons profissionais quanto eles eram fora da escola. Esses professores ministravam grandes aulas expositivas e palestras sobre algum assunto, onde procuravam ilustrar como um profissional deveria atuar na prática.

A qualidade do trabalho exercido pelo professor

\begin{abstract}
em nenhum momento era questionada, por exemplo, perguntava-se se o professor tinha transmitido bem a matéria, se havia sido claro em suas explicações, se estabelecera uma boa comunicação com o aluno, se o programa estava adaptado às necessidades e aos interesses dos alunos, se o professor dominava minimamente as técnicas de comunicação. Isso tudo, aliás, era percebido como supérfluo, porque, para ensinar, era suficiente que o professor dominasse muito bem apenas o conteúdo da matéria a ser transmitida (MASETTO, 1998, p.12).
\end{abstract}

Contudo, a situação mudou, e a recente literatura que trata sobre o professor universitário aponta para a ampliação e configuração de novas características para a docência universitária.

Agora, alguns estudos destacam que a docência para este nível passa a englobar todas as atividades desenvolvidas pelos professores, que estão orientados para a formação de seus alunos apoiando-se neles mesmos para aplicar a dinâmica da interação de diferentes processos que respaldam o modo como os professores concebem o conhecer, o fazer, o ensinar e o aprender (CUNHA, 1989; PIMENTA; ANASTASIOU, 2002; PACHANE, 2003; ZABALZA, 2004; VEIGA, 2006; ISAIA, 2006). 
Zabalza (2004) aponta que, para falar sobre a docência é necessário levar em consideração as transformações pelas quais o cenário universitário vem passando, como consequência das mudanças que se verificam no mundo contemporâneo. Dentre as mais significativas, destacam-se:

- de um bem cultural, a Universidade passou a ser um bem econômico;

- de um lugar reservado para poucos, tornou-se um lugar para o maior número possível de pessoas;

- de um bem direcionado ao aprimoramento de indivíduos, tornou-se um bem cujo beneficiário é o conjunto da sociedade;

- e ainda transformou-se em mais um recurso do desenvolvimento social e econômico dos países, submetendo-se as mesmas leis políticas e econômicas.

Pachane (2003) e Veiga (2006) apontam que a docência universitária requer formação profissional para o seu exercício, conhecimento específico para exercê-la ou, no mínimo, a aquisição de conhecimentos e das habilidades necessárias à atividade docente para melhorar sua qualidade.

Veiga (2006) ainda destaca que a docência universitária está ligada à inovação, quando rompe com a forma conservadora de ensinar, aprender, pesquisar e avaliar; reconfigura saberes, procurando superar as dicotomias entre conhecimento científico e senso comum, ciência e cultura, educação e trabalho, teoria e prática, etc.; explora novas alternativas teóricometodológicas em busca de outras possibilidades de escolhas; procura a renovação da sensibilidade ao alicerçar-se na dimensão estética, no novo, no criativo, na inventividade; e, por fim, ganha significado quando é exercida com ética.

Uma das preocupações apontadas pela literatura frente à docência na universidade é o individualismo. Zabalza (2004) mostra esta característica como um obstáculo à formação e o trabalho docente, e salienta que alguns professores do ensino superior são dominados pela "síndrome de ensinar à minha maneira".

Segundo Masetto (2003), essa constatação está associada ao fato de que o bom professor é aquele que tem grande domínio do conteúdo e sabe explicar aos alunos. Como um reflexo disso, verifica-se quando os professores vão elaborar um plano de ensino em conjunto com outros professores. Em uma situação como esta sentem-se perdidos, apenas falam de suas matérias, de seus horários, seus conteúdos, etc. 
O professor é mais "valorizado na avaliação da qualidade docente pela produtividade acadêmica, ou seja, a titulação, o trabalho na pós-graduação, a condução de pesquisas, a participação em eventos científicos e a qualidade de publicações produzidas pelo pesquisador" (PACHANE, 2003, p. 45).

\begin{abstract}
do mesmo modo que os cursos de graduação têm sido classificados [...] e os programas e cursos de pós-graduação têm sido referenciados por notas de 3 a 7 , a produção docente tem sido classificada por critérios quantitativos. Os artigos científicos tem sido valorizados de acordo com o periódico que vincula, isto é, caso esteja indexado internacionalmente ou pelo "Qualis/Capes". [...] o próprio docente é valorizado pela inserção na pós-graduação, pelo número de orientandos, artigos e livros publicados e, principalmente, pela bolsa "produtividade em pesquisa" que consegue por méritos próprios (BOSI, 2004, p. 1516-1517).
\end{abstract}

Desta forma, "os professores veem a si mesmos mais como pesquisadores (no campo científico) ou como profissionais (no campo aplicado) do que professores de fato" (ZABALZA, 2004, p. 114).

A legislação atual, ao propor que "a preparação para o exercício do magistério superior far-seá em nível de pós-graduação, prioritariamente em programas de mestrado e doutorado" (LDB 9.394/96, art. 66), deixa a formação docente, em particular a prática pedagógica, a cargo de cada instituição. E as instituições estão propondo palestras, cursos e semanas pedagógicas para preparar o professor.

A inserção de TIC na prática docente provoca demandas que vão além da organização e da rotina de sala de aula. Os estudos de Penteado-Silva (1997) e Penteado (1999; 2000), apresentam algumas delas, a saber: mudanças na organização do espaço físico, na carga de trabalho, nas relações entre professores e alunos, nas emoções, no papel do professor, na organização do currículo, a formação do professor, entre outras.

Porém, como argumenta Alegre (2005), as mudanças necessárias para que se use TIC não estão ocorrendo porque as instituições não possibilitam a operacionalização do seu uso.

Essa mesma autora argumenta que, na prática docente, a TIC permite maior potencial pedagógico para a aprendizagem, mas aponta algumas dificuldades, principalmente no que diz respeito ao aumento da dedicação do professor, tornando-se "necessário um repensar no ajuste no regime de trabalho docente, devido ao maior tempo de dedicação do professor" (ALEGRE, 2005, p. 198).

Assim, tomando por base a literatura específica que trata sobre o uso de TIC, recomenda que o professor tenha a oportunidade de estudar os conteúdos matemáticos de forma diferenciada 
da tradicional, de trabalhar em grupos, de refletir sobre os problemas da prática com apoio de teorias (PENTEADO-SILVA, 1997).

\section{Professores universitários que usam TIC nas aulas de matemática}

Com base nas entrevistas realizadas com professores universitários que utilizam TIC para ensinar Cálculo, esta seção traz uma discussão sobre os seguintes aspectos: tempo de docência no ensino superior; tempo que usa TIC; formação dos professores; instituições em que trabalham; a motivação; o preparo e o envolvimento dos professores.

Inicio destacando na tabela 1 o tempo de docência dos professores no ensino superior.

Tabela 1 - Tempo de docência no ensino superior

\begin{tabular}{cc}
\hline $\begin{array}{c}\text { Tempo de Docência no ensino superior } \\
\text { (anos) }\end{array}$ & Professores \\
\hline Menos de 10 & Rosa e Roberta \\
\hline De 11 a 20 & Bárbara, Marta, Renata, Solange e Wagner \\
\hline De 21 a 30 & Neide e Sandro \\
\hline Acima de 30 & Ronaldo, Rose, Valdemar e Verônica. \\
\hline
\end{tabular}

De todos os participantes, apenas dois têm menos de dez anos de docência no ensino superior. O tempo médio de docência dos depoentes está em torno de 21,8 anos e os professores com maior tempo de docência neste nível de ensino superam os 30 anos. Isso indica que a maioria dos professores tem certa experiência na docência do ensino superior.

Sobre o tempo que usa TIC, os professores que a usam por um período maior são Neide, Rose, Sandro, Solange, Wagner e Verônica, enquanto os depoentes que usam há menos tempo são Rosa e Ronaldo. Constatando que a média de uso está em torno de 9,8 anos. Na tabela 2, é apresentado um resumo desses dados. 
Tabela 2 - Tempo que usa TIC

\begin{tabular}{cc}
\hline Tempo que usa a TIC em suas aulas (anos) & Professores \\
\hline Menos de 5 & Ronaldo e Rosa \\
\hline 6 a 10 & Bárbara, Marta, Roberta e Valdemar. \\
\hline 11 a 15 & $\begin{array}{c}\text { Neide, Rose, Renata, Sandro, Solange, } \\
\text { Wagner e Verônica. }\end{array}$ \\
\hline
\end{tabular}

Ao comparar os dados entre as tabelas 1 e 2, é possível observar que Ronaldo, apesar de ser um dos professores com mais tempo de docência no ensino superior, destaca-se por ser um dos mais novos entre os depoentes a usar TIC. Os demais professores, com exceção de Rosa e Roberta, começaram a usar em suas aulas de Cálculo depois de mais de dez anos na docência. Sobre a área de formação, os dados mostram que todos os professores são doutores e estão distribuídos nas seguintes áreas do conhecimento, como é evidenciado na tabela 3.

Tabela 3 - Área de formação

\begin{tabular}{cc}
\hline Área de formação & Professores \\
\hline Educação & Bárbara e Rosa \\
\hline Educação Matemática & Neide, Renata, Roberta, Rose e Valdemar \\
\hline Matemática Aplicada & Marta, Ronaldo, Sandro e Solange \\
\hline Matemática Pura & Verônica \\
\hline Física & Wagner \\
\hline
\end{tabular}

É importante destacar que, independentemente da formação que o professor possa ter, isto não garante que fará a inserção de TIC em sua prática docente, mas pode abrir espaços para conhecer suas potencialidades e limitações (PENTEADO, 2000).

Outro aspecto identificado pelos depoentes está ligado às diferentes instituições onde trabalham, como destacado na tabela 4. 
Tabela 4 - Tipos de IES em que os professores trabalham

\begin{tabular}{cccc}
\hline & Pública & $\begin{array}{c}\text { Universidade } \\
\text { Estadual }\end{array}$ & $\begin{array}{c}\text { Bárbara, Marta, Rosa, } \\
\text { Solange, } \\
\text { Verônica, Wagner. }\end{array}$ \\
\cline { 2 - 3 } $\begin{array}{c}\text { Tipo de IES } \\
\text { em que os } \\
\text { professores } \\
\text { trabalham }\end{array}$ & Particular & $\begin{array}{c}\text { Universidade } \\
\text { Federal }\end{array}$ & Ronaldo, Sandro, \\
\cline { 2 - 4 } & & Universidade & $\begin{array}{c}\text { Neide, Roberta, Rose, } \\
\text { Valdemar, }\end{array}$ \\
\cline { 2 - 4 } & Pública e Particular & Universidade & Neide, Valdemar, \\
\cline { 2 - 3 } & & Faculdade Pública & Renata \\
\hline
\end{tabular}

Os dados também mostram que, dos treze professores, Neide, Renata e Valdemar trabalham em mais de uma instituição. Esse fato, de os professores trabalharem em algumas outras universidades, é algo que acontece muito frequentemente no Brasil. Trata-se de um conjunto de necessidades que ocorrem em consequência das mudanças sociais e econômicas que o mundo contemporâneo vem sofrendo (ZABALZA, 2004).

Nestas instituições, os depoentes ministram suas aulas sob dois tipos de condições de trabalho: a dedicação exclusiva e a dedicação parcial. A tabela 5 comprova que mais da metade dos entrevistados trabalham em regime de dedicação exclusiva.

Tabela 5 - Regime de trabalho

\begin{tabular}{cc}
\hline Regime de trabalho & Professores \\
\hline Dedicação exclusiva & $\begin{array}{c}\text { Bárbara, Marta, Ronaldo, Rosa, Sandro, } \\
\text { Solange, Verônica. }\end{array}$ \\
\hline Dedicação parcial & $\begin{array}{c}\text { Neide, Renata, Roberta, Rose, Valdemar, } \\
\text { Wagner. }\end{array}$ \\
\hline
\end{tabular}

Mas, afinal, o que motivou esses professores a usarem TIC em sua prática pedagógica?

A interpretação dos dados direciona para a questão da necessidade. Esta constatação está relacionada a alguns fatores como manter o emprego, ampliar abordagens pedagógicas, estar em sintonia com o que ocorre fora da escola e o mercado de trabalho. 
Em algumas situações, o uso educacional de TIC acontece pela imposição de pessoas que exercem cargos administrativos nas IES, como é o caso da instituição onde Valdemar trabalha, que é o coordenador do curso quem propõe o uso da tecnologia.

“o coordenador geral da Matemática que propôs, então, que desse aula para os alunos no curso de sábado e para os alunos do $3^{\circ}$ e do $5^{\circ}$ período e, depois, $4^{o}$ período e $6^{o}$ período no laboratório de informática, usando o Winplot. Daí em diante, passei a usar sempre." (Valdemar)

Para outros professores, como Renata e Rose, por exemplo, o uso de TIC está vinculado a um interesse pessoal. Isto pode ser identificado nas falas a seguir:

"Foi aos poucos, eu sou bastante antiga aí. Então, conforme foram aparecendo possibilidades de utilizar esses recursos e eu fui me informando sobre eles, eu fui tentando inserir nas aulas.” (Renata)

"Eu só comecei a trabalhar com esse tipo de recurso por volta de 94, 95 quando eu comecei a me interessar com o uso da informática na área educação.” (Rose)

Outra necessidade apontada pelos dados está relacionada ao ensino de Cálculo e sua futura participação na realidade profissional dos alunos, conforme esclarece Bárbara, a seguir:

“... a gente fica querendo que o aluno aprenda técnicas de integração, por exemplo. Você gasta meses lá com vários tipos de técnicas, bom. Qual é o engenheiro, que formado, que tá lá fazendo o seu projeto ou sei lá? O que é? Aparece no negócio, na coisa dele uma integral e ele vai pegar lápis e papel para fazer essa integral?E se aparece uma integral, mas se aparece uma conta, qualquer operação, ele faz na calculadora. Entendeu? Então já nessa época eu comecei a ficar preocupada com essa questão.” (Bárbara)

"Revendo os fatos de que essa ferramenta [a TIC] existe, tá ai na praça, não adianta fechar o olho, fazer de conta que não tem, ou que o menino só vai treinar no segundo ano [ensino médio] da escola. Entendeu? O meu aluno lá [de outra universidade em que trabalha], que não tem, mas poderia ter na escola básica, na escola fundamental, provavelmente já sabe usar a calculadora, por quê? Porque no celular tem calculadora, entendeu? E ai eu vou falar não? Mas na aula de matemática não é pra usar calculadora? Como é que faz? Entendeu? Ai a matemática mais uma vez vira uma coisa chata, porque um negócio que era fácil, apertar o botãozinho e eu sabia o resultado, agora não, tem que fazer na...” (Bárbara) 
$\mathrm{O}$ uso de TIC no ensino superior tem sido fortemente recomendado por especialistas, principalmente no ensino de Cálculo (BARUFI, 1999; SOUZA JR. 2000; ARAÚJO, 2002), pois amplia as possibilidades de trabalhar com diferentes atividades, tais como aquelas que envolvem o uso de tabelas, gráficos e expressões algébricas de forma rápida e articulada. Isso contribui para a exploração dos diferentes conceitos matemáticos, como indica a fala a seguir:

“... foi mais por dificuldade de cálculo no sentido das contas, dos cálculos numéricos que os alunos precisavam fazer. Inicialmente foi isso, e depois que eu comecei a ler sobre essas coisas e me interessar um pouco mais, foi pela possibilidade de aproveitar outras formas de representação que, sem essas tecnologias, eu não tinha condição de fazer coisas assim que era - a representação gráfica de funções. Então, ela era mais eficiente, permitia trabalhar com funções não usuais, transitar sobre essas representações e acho que foi isso que me levou a utilizar." (Neide)

“Bom, eu acho que, em termos de visualização, de conceitos matemáticos, eles são ótimos e deram outro jeito de tratar a matemática através do conceito gráfico, representando graficamente. E, como eu disse, eu comecei a trabalhar na Arquitetura, e o visual deles é muito forte e alguns problemas me foram colocados lá. Então eu achei que era mais importante eles saberem lidar com um gráfico de uma função do que construir o gráfico, a partir daí eu comecei a me interessar a usar os recursos [tecnológicos] e provocar.” (Rose)

Sobre a preparação para lidar com TIC, algumas situações são apresentadas. No caso de Wagner, a pós-graduação foi uma preparação para a incorporação dessa tecnologia no ensino de Cálculo. Como é evidenciado na fala a seguir:

“Então, já durante o doutorado. Eu já fui do mestrado com esse preparo. Eu fiz meu mestrado, eu terminei meu mestrado em 89 e eu fiz um processo algoritmo feito num software chamado Reduce, que é um software de computação algébrica igual ao Maple, mas mais antigo, e eu fiz no meu mestrado esse tipo de coisa. Então eu já tinha um contato com a computação algébrica desde 88. Desde 1988 eu já tinha esse contato. E, no doutorado, eu fui já direcionado a fazer o uso de sistemas de computação simbólica em relatividade geral, pra se calcular determinadas quantidades. Então é um ferramental natural da minha área.” (Wagner) 
Renata argumenta que sua preparação para lidar educacionalmente com a TIC se deu aos poucos e nunca teve a companhia de outros professores para discutir sobre o assunto. Para superar esta dificuldade, participa de cursos e estabelece parcerias com os alunos, pois

“(...) os alunos descobrem muitas coisas que, às vezes, a gente não sabia. Eles têm muita familiaridade com informática, então eles ajudam a descobrir. Então, não tenho feito nenhum curso específico, eu vou explorando meio sozinha.” (Renata)

Os docentes Rosa, Rose, Sandro, Bárbara e Roberta apontam que, para se atualizar, participam de discussões que ocorrem nos encontros apoiados pela Sociedade Brasileira de Educação Matemática - SBEM; pela Sociedade Brasileira de Matemática Aplicada e Computacional - SBMAC; e pela Sociedade Brasileira de Matemática - SBM. Além destes, procuram participar de grupos de estudos na própria universidade onde trabalham, e alguns deles chegam a ir para outras instituições para participar de grupos de pesquisa na área de educação matemática e o uso de TIC. Dessa forma, interagem em um ambiente propício para se sentirem estimulados a se arriscar em uma nova prática e a entrar em uma "zona de risco" (PENTEADO, 2001).

Ainda existem casos de professores que se atualizam e se preparam para o uso de TIC por conta própria. Eles estudam em livros, pesquisam na Internet à procura de cursos e outras ferramentas. A fala de Neide demonstra esta postura autônoma:

“(...) nós professores nos virávamos, você aprendia sozinho a mexer, mesmo nessa instituição que era bastante informatizada, sala de aula toda informatizada, nós não tínhamos o suporte que deveríamos ter quando éramos colocados na sala de aula, muitas coisas nós aprendemos mexer sozinhos, errando e acertando e tendo dificuldade e aprendendo, tive treinamentos breves sobre utilização das coisas, só.” (Neide)

Outro destaque importante durante as entrevistas, é para a existência de alguns casos em que a preparação se deu pelo envolvimento com colegas nas instituições onde trabalham, como é o caso de Ronaldo, a seguir:

“(...) a gente fez um pequeno treinamento que foi feito entre nós. Isso aí não tem problema, você pega o manual, lá no manual tem tudo, comandos, programação. Então nós fizemos um mini curso, os professores, e uma boa parte dos professores participaram." (Ronaldo) 
Nesse sentido, existe o caso de Marta, Solange e Verônica, que trabalham em uma mesma universidade. As professoras relatam que o envolvimento se deu por meio de um trabalho coletivo no uso de TIC entre elas e os alunos, possibilitando a produção de saberes e o enriquecimento no que diz respeito ao processo de ensinar e aprender matemática.

Os aspectos levantados acima (tempo de docência; tempo de utilização de TIC; a formação dos professores; as instituições onde trabalham; as condições do trabalho docente; a motivação; o preparo e o envolvimento dos professores) formam um conjunto de indícios que direciona à conclusão de que a união desses aspectos é responsável pela constituição do perfil do professor que faz uso de TIC.

\section{Considerações finais}

Este texto traz resultados de uma pesquisa que teve como objetivo compreender como os professores do ensino superior estão utilizando TIC em suas aulas de Cálculo. Com base nos dados oriundos de entrevistas com professores universitários, foram apresentados alguns aspectos sobre o tempo de docência no ensino superior, o tempo de uso, a formação, as diferentes instituições onde os professores trabalham, o regime de trabalho, a motivação para que utilizassem TIC em suas aulas, a preparação para o uso, e a atualização para se adequar as tecnologias.

$\mathrm{Na}$ análise dos dados foi possível identificar que a escolha do professor pelo uso de tecnologia tem uma justificativa de nível mais pragmática, no sentido de que necessitam manter o emprego e uma justificativa em nível mais conceitual, que está relacionada com a visão de educação que os professores possuem. Neste nível, eles falam sobre ampliar abordagens pedagógicas, de estar em sintonia com o que ocorre fora da escola e de atender ao mercado de trabalho. A literatura tem mostrado que o uso de TIC, principalmente para o ensino de Cálculo, é importante para ampliar as possibilidades de trabalhar atividades por diferentes representações, tais como: tabela, gráficos, expressões algébricas, de forma rápida e articulada (BARUFI, 1999; SOUZA JR, 2000; ARAÚJO, 2002).

As mudanças promovidas pela sociedade da informação vêm causando alterações na postura dos professores que querem se adequar e preparar seus alunos para atuarem nesta sociedade, como é o caso dos participantes dessa pesquisa. 
Pesquisadores como: Masetto (2003) e Cunha (1998), entre outros, indicam que apenas o Doutoramento não é suficiente para que o professor se mantenha atualizado para atuar na docência.

Neste estudo, em que todos os professores são doutores em alguma das áreas do conhecimento, apenas o docente Wagner diz que o Doutorado o ajudou, impulsionando-o para o uso de TIC. Para os demais professores isso ocorreu durante a prática docente e por iniciativa própria.

Masetto (2003) aponta a necessidade de mais discussão na Universidade a respeito do currículo dos cursos e a formação do professor universitário. Uma das possibilidades é propiciar ao professor um contato mais intenso com a TIC, desde a sua formação inicial.

Com a pesquisa, o presente trabalho visa apresentar como os professores de matemática do ensino superior estão fazendo uso de TIC. Dessa forma, talvez possa servir de estímulo aos demais professores e pesquisadores na área. Ainda, revela o anseio de que os resultados deste artigo possam apontar a necessidade de se pensar a formação continuada de professores universitários, de forma mais sistematizada e articulada com a prática. 


\section{Referências}

ALEGRE, L. M. P. (2005). Utilização das tecnologias da informação e da comunicação, na prática docente, numa instituição de ensino tecnológico. Tese (Doutorado em Educação) - Universidade Estadual de Campinas, Campinas.

ARAÚJO, J. Cálculo, Tecnologias e Modelagem Matemática: As Discussões dos Alunos. Tese (Doutorado em Educação Matemática) - Universidade Estadual Paulista. Rio Claro, 2002.

BARUFI, M. C. B. A construção / negociação de significados no curso universitário inicial de Cálculo Diferencial e Integral. 1999. Tese (Doutorado em Educação) Universidade de São Paulo, São Paulo, 1999.

BORBA, M. C.; PENTEADO, M. G. Informática e Educação Matemática. $3^{\text {a }}$ Edição.Belo Horizonte: Editora Autêntica, 2001.

BOSI, A. P. A precarização do trabalho docente nas instituições de ensino superior do Brasil nesses últimos 25 anos. Educação \& Sociedade, vol. 28, $\mathrm{n}^{\circ}$ 101. Campinas: Unicamp, set/dez. 2004, p.1503-1523.

CUNHA, M. I. O bom professor e sua prática. Campinas, SP: Papirus, 1989.

O professor universitário na transição de paradigmas. Araraquara, SP: JM, 1998.

ISAIA, S. M. A. Desafios a docência superior: pressupostos a considerar. Docência na educação superior. Brasília: Inep, 2006. p.63-84.

KOGA, M. T. (1998).Uma Análise do Discurso De Alguns Professores de Cálculo Diferencial e Integral do Curso de Licenciatura em Matemática. Dissertação (Mestrado em Educação Matemática)- Instituto de Geociências e Ciências Exatas, Universidade Estadual Paulista. Rio Claro.

MASETTO, M. T. Professor universitário: um profissional da educação na atividade docente. In: MASETTO, M. T. (org.). Docência na universidade. Campinas, SP: Papirus, 1998. p. 926.

Competências Pedagógicas do professor universitário. São Paulo: Summus, 2003.

NASSER, L. (2004). Educação Matemática no ensino superior. Mesa redonda: "Educação Matemática no ensino superior”, Anais do VIII ENEM. Pernambuco: UFPE.

PALIS, G. R. (1995). Computadores em Cálculo uma alternativa que não se justifica por si mesma. Temas \& Debates, Sociedade Brasileira de Educação Matemática, ano VIII, $6^{\mathbf{a}}$ edição, p. 22-38.

PACHANE, G. G. A importância da formação pedagógica para o professor universitário - a experiência da UNICAMP. Tese (Doutorado em Educação) - Universidade Estadual de Campinas, Campinas, 2003. 
PENTEADO SILVA, M. G. O computador na perspectiva do desenvolvimento profissional do professor. Tese (Doutorado em Educação) - Universidade Estadual de Campinas, Campinas, 1997.

PENTEADO, M. G. Novos Atores, Novo Cenário: Discutindo a inserção dos computadores na profissão docente. In: BICUDO, M. A. V. (org.). Pesquisa em Educação Matemática: Concepções \& Perspectivas. São Paulo: Editora da UNESP, 1999, p.297-313.

. (2001). Computer-based learning environments: risks and uncertainties for teachers. In: Ways of Knowing, Inglaterra, v. 1, n. 2, p.23-35.

Possibilidades para a formação de professores de Matemática. In: PENTEADO, M. G; BORBA, M. C. (Orgs.). A Informática em Ação: formação de professores, pesquisa e extensão. 1. ed. São Paulo: Olho Dágua, 2000. v. p. 23-34.

PIMENTA, S. G.; ANAStASIOU, L. G. C. Docência no ensino superior. São Paulo: Cortez, 2002. (Coleção Docência em Formação V.1).

SOUZA JR., A. J. Trabalho coletivo na universidade: Trajetória de um grupo no processo de ensinar e aprender Cálculo Diferencial e Integral. Tese (Doutorado em Educação) Universidade Estadual de Campinas, Campinas, 2000.

VEIGA, I. P. A. Docência universitária na educação superior. Docência na educação superior. Brasília: Inep, 2006. p.85-96.

ZABALZA, M. A. A. O ensino universitário: seu cenário e seus protagonistas. Porto Alegre: Artmed, 2004. 